\title{
Systematic review with meta-analysis: cytokines in fibromyalgia syndrome
}

\author{
Nurcan Üçeyler ${ }^{1 *}$, Winfried Häuser ${ }^{2,3}$ and Claudia Sommer ${ }^{1}$
}

\begin{abstract}
Background: To perform a systematic review and meta-analysis on cytokine levels in patients with fibromyalgia syndrome (FMS).

Methods: Through December 2010 we systematically reviewed the databases PubMed, MEDLINE, and PsycINFO and screened the reference lists of 22 review articles for suitable original articles. Original articles investigating cytokines in patients with FMS were included. Data were extracted by two independent authors. Differences of the cytokine levels of FMS patients and controls were summarized by standardized mean differences (SMD) using a random effects model. Study quality was assessed applying methodological scores: modified Center of Evidence Based Medicine, Newcastle-Ottawa-Scale, and Würzburg Methodological Quality Score.
\end{abstract}

Results: Twenty-five articles were included investigating 1255 FMS patients and 800 healthy controls. Data of 13/25 studies entered meta-analysis. The overall methodological quality of studies was low. The results of the majority of studies were not comparable because methods, investigated material, and investigated target cytokines differed. Systematic review of the selected 25 articles revealed that FMS patients had higher serum levels of interleukin (IL)- 1 receptor antagonist, IL-6, and IL-8, and higher plasma levels of IL-8. Meta-analysis of eligible studies showed that FMS patients had higher plasma IL-6 levels compared to controls (SMD $=-0.34[-0.64,-0.03] 95 \% \mathrm{Cl} ; \mathrm{p}=0.03)$. The majority of investigated cytokines were not different between patients and controls.

Conclusions: The pathophysiological role of cytokines in FMS is still unclear. Studies of higher quality and with higher numbers of subjects are needed.

\section{Background}

Fibromyalgia syndrome (FMS) is a complex of symptoms that, according to the criteria of the American College of Rheumatology (ACR), is associated with chronic widespread pain and at least eleven positive tender points out of 18 [1]. Additional symptoms like fatigue, pain associated sleep disturbance, depression, or gastrointestinal disorders are frequently reported [2]. The pathophysiology of FMS is incompletely understood and although the syndrome can be characterized by an identifiable group of signs and symptoms, there is no recognized etiologic agent and no consistent anatomical alteration that would qualify FMS as a disease (e.g. Stedman's online medical dictionary http://www.stedmans. com).

\footnotetext{
* Correspondence: ueceyler_n@klinik.uni-wuerzburg.de

'Department of Neurology, University of Würzburg, Josef-Schneider-Str. 11, 97080 Würzburg, Germany

Full list of author information is available at the end of the article
}

With an estimated prevalence of $0.5 \%$ to $5.8 \%$ in the general population of North America and Europe [3,4], FMS is a frequent condition and better pathophysiological knowledge is warranted to more effectively direct treatment. Although a large number of studies on the pathophysiology of FMS have been published, there is still no overall concept explaining all aspects of FMS. An imbalance of pro- and anti-inflammatory cytokines is assumed to play a role in the induction and maintenance of pain [5] and several laboratories have investigated cytokine levels in patients with FMS with diverse results. In non-systematic reviews the potential pathophysiological role of cytokines has been discussed with discrepant results [6,7]. A systematic review with a quantitative synthesis of the cytokine profiles of FMS patients compared to controls had not been performed until now. The aims of this systematic review therefore were to systematically and quantitatively review data on
C Biomed Central

๑ 2011 Üçeyler et al; licensee BioMed Central Ltd. This is an Open Access article distributed under the terms of the Creative Commons Attribution License (http://creativecommons.org/licenses/by/2.0), which permits unrestricted use, distribution, and reproduction in any medium, provided the original work is properly cited. 
pro- and anti-inflammatory cytokines in FMS patients considering and assessing study quality.

\section{Methods \\ Setting}

The literature search was initiated as part of the development of an evidence-based interdisciplinary guideline for the diagnosis and therapy of FMS on behalf of the Association of the Scientific Medical Societies of Germany (AWMF) coordinated by the German Interdisciplinary Association of Pain (DIVS) [8]. The search was later expanded and extended (see below).

\section{Searches}

A literature search for original research articles on the pathophysiology of FMS was performed through December 2010 and the following databases were screened: PubMed, MEDLINE, and PsycINFO. The keywords (all languages) "fibromyalgia", "fibromyalgia syndrome", "chronic widespread pain" were used in combination with "cytokine", with "cytokine" AND "pathophysiology", and also with "review". Additionally, the reference sections of 22 review articles that were found using this search strategy were screened for possibly suitable original articles.

\section{Inclusion and exclusion criteria}

We only included original full text articles investigating the pathophysiological role of cytokines in FMS and excluded the following articles that appeared upon the search strategy detailed above: double hits, reviews, letters to the editor, papers investigating other disorders, articles in Danish, all articles that did not investigate cytokines. First, the titles and abstracts of all articles found were screened for suitability; the initially chosen articles were then screened again checking the entire article.

\section{Data extraction}

Two authors independently screened the titles and abstracts of potentially eligible articles that were detected by the search strategy described above. The full text of the selected studies was examined. For data extraction two authors (NÜ, CS) independently used standard extraction forms. All authors cross-checked the extraction forms for correctness. Data were categorized for the material investigated. Blood measurements were performed in serum, plasma, and whole blood; accordingly these data were first assessed separately and then all study results on "blood" were compared.

\section{Quality assessment}

For evaluating the quality of the selected studies we applied two validated scales: the Level of Evidence of the Oxford Center for Evidence-based Medicine (CEBM, http://www.cebm.net/index.aspx?o=1025) and the Newcastle-Ottawa Quality Assessment Scale (NOS) http:// www.ohri.ca/programs/clinical_epidemiology/oxford.asp.

We modified the CEBM to make it applicable for scientific papers investigating pathophysiological aspects with bench research (Table 1). Additionally, we aimed at evaluating the quality of the laboratory methods used. To our knowledge there is no standardized rating scale to assess the quality of laboratory methods in scientific papers. Therefore we created the Würzburg Methodological Quality Score (W-MeQS, Table 2). W-MeQS consists of twelve items that are relevant for high quality of a laboratory method. For each item fulfilled one point is given; the score is the sum of all points achieved divided by the number of items that were applicable. If the target of interest was measured by just one method this score marks the end score. If more than one method was used, a subscore is calculated for each method as described and the end-score is calculated as mean of the subscores. The scores were evaluated as follows: $\leq 0.4$ : low quality; > 0.4 medium quality; $\geq 0.8$ high quality.

\section{Data synthesis and analysis}

Meta-analysis was performed using RevMan analysis software (RevMan 5.1.2) of the Cochrane Collaboration [9]. Standardized mean differences (SMD) were calculated by means and standard deviations for each cytokine.

\section{Results}

\section{Study selection}

For the number of found, selected, excluded and finally included articles see the algorithm shown in Figure 1.

The initial literature search retrieved the following numbers of articles: PubMed: 281; MEDLINE: 69; PsycINFO: 2. After exclusion of double hits 115 articles were chosen and the titles and abstracts were screened for suitability. The following 90 articles were excluded: reviews $(n=42)$, papers investigating other disorders ( $\mathrm{n}$ $=26)$, papers not investigating cytokines $(n=11)$, letters to the editor $(n=4)$, double publications $(n=3)$, treatment studies $(\mathrm{n}=3)$, and one article in Danish. The screening of the reference sections of 22 review articles did not provide further original articles. Finally, 25 articles were selected for our systematic review [10-34]. A total of 1255 patients with FMS, 180 patients in disease control groups, and 800 healthy controls were investigated.

Of these 25 articles, two articles were not suitable for meta-analysis because no healthy control group was investigated [11,26]; seven articles could not be included, because mean and standard deviations were not given in the article or could not be calculated (e.g. 
Table 1 Levels of CEBM modified for scientific papers investigating disease pathophysiology with bench research.

\begin{tabular}{|c|c|c|c|c|}
\hline Level & Differential diagnosis/symptom prevalence study & Blinded & Controls & Remark/example \\
\hline $1 \mathrm{a}$ & Systematic review of prospective cohort studies & NR & NR & No systematic reviews available \\
\hline $1 \mathrm{~b}$ & Prospective cohort study with good follow-up & NR & Implicit & $\begin{array}{l}\text { An item is assessed (e.g. breast implant) and the } \\
\text { occurrence of FMS is followed prospectively }\end{array}$ \\
\hline$\overline{1 c}$ & All or none case series & $\begin{array}{l}\text { Test and } \\
\text { assessment of } \\
\text { results }\end{array}$ & Obligatory & $\begin{array}{l}\text { All patients with low IL-4 have FMS, none has } \\
\text { high IL-4 }\end{array}$ \\
\hline $1 d$ & $1 \mathrm{c}$ & $\begin{array}{l}\text { Test or } \\
\text { assessment of } \\
\text { results }\end{array}$ & Obligatory & 1c \\
\hline \multirow[t]{2}{*}{$2 \mathrm{a}$} & Systematic review (with homogeneity) of & NR & NR & No systematic reviews available \\
\hline & $2 \mathrm{~b}$ and better studies & & & \\
\hline $2 b$ & Retrospective cohort study, or poor follow-up & NR & Implicit & $\begin{array}{l}\text { FMS patients are investigated now, if they have } \\
\text { had breast implants in the past; large size studies }\end{array}$ \\
\hline $2 c$ & Ecological studies & $\begin{array}{l}\text { Test and } \\
\text { assessment of } \\
\text { results }\end{array}$ & Implicit & $\begin{array}{l}\text { FMS patients are investigated simultaneously, if } \\
\text { they have FMS and if they have low IL-4 levels. }\end{array}$ \\
\hline$\overline{2 d}$ & $2 c$ & $\begin{array}{l}\text { Test or } \\
\text { assessment of } \\
\text { results }\end{array}$ & Implicit & $2 c$ \\
\hline $3 a$ & $\begin{array}{l}\text { Systematic review (with homogeneity) of } 3 \mathrm{~b} \text { and } \\
\text { better studies }\end{array}$ & & & No systematic reviews available \\
\hline \multirow[t]{2}{*}{$3 b$} & $\begin{array}{l}\text { Non-consecutive cohort study, or very limited } \\
\text { population }\end{array}$ & $\begin{array}{l}\text { Test and } \\
\text { assessment of } \\
\text { results }\end{array}$ & Obligatory & $\begin{array}{l}\text { FMS patients and controls (limited population) } \\
\text { are now investigated if they have low } \mathrm{L}-4\end{array}$ \\
\hline & & & & levels \\
\hline $3 c$ & $3 b$ & $\begin{array}{l}\text { Test or } \\
\text { assessment of } \\
\text { results }\end{array}$ & Obligatory & $3 b$ \\
\hline $3 d$ & $1 c, 2 c, 3 b$ & Not blinded & Obligatory & \\
\hline 4 & Case series or superseded reference standards & & $\begin{array}{l}\text { All studies } \\
\text { without control } \\
\text { group }\end{array}$ & Case series with historical controls; case reports \\
\hline 5 & $\begin{array}{l}\text { Expert opinion without explicit critical appraisal, or } \\
\text { based on physiology, bench research or "first } \\
\text { principles" }\end{array}$ & NR & & \\
\hline
\end{tabular}

Abbreviations: CEMB: Oxford Center for Evidence-based Medicine FMS: fibromyalgia syndrome; NR: not relevant

Table 2 Würzburg Methodological Quality Score (W-MeQS) for the assessment of the quality of laboratory methods.

\begin{tabular}{ll}
\hline 1 & Item \\
\hline 2 & Standardized method OR citation OR new method with adequate description including 2-5? \\
\hline 3 & Adequate description of the method itself? \\
\hline 5 & Sensitivity limits of the method declared? \\
\hline 6 & Adequate internal controls measured? \\
\hline 8 & Adequate negative controls measured? \\
\hline 9 & Adequate number of samples investigated? \\
\hline 10 & Adequate comparison with the control group? \\
\hline 11 & All reagent information given? \\
\hline
\end{tabular}






Figure 1 Algorithm of study selection. The Figure displays the details of the study search and selection process.

from the standard error of the mean) and were not provided upon request $[10,13,15,20,21,25,27]$. Finally, 16 articles were principally suitable for meta-analysis [12,14,16-19,22-24,28-34]. These articles were then screened for suitability to be categorized in groups of articles having investigated the same cytokine with the same method in the same material; three of the 16 articles could not be categorized in one of the subgroups (see below) and therefore could not enter meta-analysis $[12,18,33]$. Thus, 13 articles were finally included in the meta-analysis. Table 3 summarizes key information of the 25 selected articles and gives the quality scores of the studies.

\section{Majority of studies with low quality}

Only three of the 25 studies (12\%) had a modified CEBM level of 3c $[14,15,19]$. Twenty-one of the 25 (84\%) studies had a modified CEBM level of 3d [10-13,16-18,20-25,27-34], and one case report of 4 (4\%) [26]. The highest NOS score reached was 4 out of 8 ; this was achieved by $5 / 25$ studies (25\%) [12,28,30,32]. Eleven out of 25 studies (44\%) reached a NOS score of
3 [11,13-17,20,24,25,31,33]; $8 / 25$ studies (32\%) had a NOS score of $2[10,18,21-23,27,29,34]$; one study had a NOS score of 1 (4\%) [26].

In the W-MeQS only $4 / 25$ studies (16\%) were of high methodological quality (score $\geq 0.8$ ) $[14,15,29,30] ; 7 / 25$ studies $(28 \%)$ were of medium quality (score $>0.4$ ) $[10,19-21,27,31,33]$, and $14 / 25$ studies $(56 \%)$ were of low quality (score $\leq 0.4)[11-13,16-18,22-26,28,32]$. Only $2 /$ 25 studies (8\%) had a high NOS and W-MeQS score $[14,15]$.

These results show that the majority of the studies were of low methodological quality.

\section{High variability of materials and methods}

In twelve studies serum [11,13,19,20,23,25,26, 28,30-32,34], in seven studies peripheral blood mononuclear cells (PBMC) $[10,12,18,21,22,24,31]$, in six studies plasma $[13,14,16,17,29,33]$, in two studies skin biopsies [15,27], and in one study whole blood [30] was investigated. Cytokine levels were investigated with ELISA in twelve studies [11-14,19,23-25,28,30,31,34], with bead-based immunoassays in five studies 
Table 3 Characteristics of all studies included in the systematic review investigating cytokines in FMS patients.

\begin{tabular}{|c|c|c|c|c|c|c|}
\hline $\begin{array}{l}\text { Author, yr. } \\
\text { Diagnosis } \\
\text { criteria }\end{array}$ & $\mathrm{N}$ patients/controls & $\begin{array}{l}\text { a) Material } \\
\text { b) Methods } \\
\text { c) Investigated targets }\end{array}$ & Results & $\begin{array}{l}\text { Modified } \\
\text { CEBM } \\
\text { level } \\
\end{array}$ & NOS & $\begin{array}{l}\text { W- } \\
\text { MeQS }\end{array}$ \\
\hline $\begin{array}{l}\text { Hader, } 1991 \\
\text { Smythe }\end{array}$ & $12 / 10$ & $\begin{array}{l}\text { a) CD4+ T-lymphocytes from PBMC } \\
\text { b) T-cell culture; stimulation } \\
\text { experiments with mitogens and } \\
\text { measurement of IL-2 secretion } \\
\text { c) IL-2 }\end{array}$ & $\begin{array}{l}\text { FMS: higher concentration of mitogen } \\
\text { was necessary to achieve optimal IL-2 } \\
\text { secretion; peak time of IL-2 secretion } \\
\text { was delayed. } \\
\text { Addition of calcium did not correct } \\
\text { the reduction in IL-2 secretion in } \\
\text { patients with FMS; addition of } \\
\text { phorbole myristate acetate led to } \\
\text { normal IL-2 secretion. }\end{array}$ & $3 d$ & 2 & 0.4 \\
\hline $\begin{array}{l}\text { Barth, } 1999 \\
\text { Wolfe, } 1985\end{array}$ & $\begin{array}{l}12 \mathrm{FMS} / 6 \text { rheumatoid } \\
\text { arthritis or osteoarthritis } \\
\text { controls/ } 6 \text { controls }\end{array}$ & $\begin{array}{l}\text { a) supernatant of PBMC } \\
\text { b) self established double sandwich } \\
\text { ELISA; } \\
\text { c) IL-4; IL-2; INF } \gamma \text {; GM-CSF; IL-5, IL-10 }\end{array}$ & $\begin{array}{l}\text { In vitro stimulation of PBMC with } \\
\text { different L-tryptophan preparations: } 6 / \\
12 \text { FMS patients, } 2 / 12 \text { controls: IL-5 } \\
\text { and IL-10 production }\end{array}$ & $3 d$ & 4 & 0.1 \\
\hline $\begin{array}{l}\text { Maes, } 1999 \\
\text { ACR }\end{array}$ & $21 / 33$ & $\begin{array}{l}\text { a) serum } \\
\text { B) ELISA } \\
\text { c) IL-6, sIL-6 R, sIL-1R, IL-1RA }\end{array}$ & $\begin{array}{l}\text { In FMS compared to controls: } \\
\text { IL-6↔ } \\
\text { SIL-6R } \\
\text { SIL-1R } \Uparrow \\
\text { IL-1RA } \Uparrow\end{array}$ & $3 d$ & 2 & 0.3 \\
\hline $\begin{array}{l}\text { Pay. } 2000 \\
\text { ACR }\end{array}$ & $\begin{array}{l}25 \mathrm{FMS} / 25 \text { chronic } \\
\text { musculoskeletal complaints/ } \\
25 \text { controls }\end{array}$ & $\begin{array}{l}\text { a) serum } \\
\text { b) ELISA } \\
\text { c) IL-1 } 1 \beta, T N F, I L-6\end{array}$ & $\begin{array}{l}\text { No difference for pro-inflammatory } \\
\text { cytokines in FMS and controls. }\end{array}$ & $3 d$ & 3 & 0.4 \\
\hline $\begin{array}{l}\text { Wallace, } \\
2001 \\
\text { ACR }\end{array}$ & $\begin{array}{l}56 / 56 \\
\text { Serum, PBMC }\end{array}$ & $\begin{array}{l}\text { a) serum, PBMC, plasma } \\
\text { b) ELISA } \\
\text { c) IL-1 } \beta, I L-2, I L-6, I L-8, I L-10, s \mid L-2 R, I L- \\
1 R A, I F N \gamma \text {, TNF }\end{array}$ & $\begin{array}{l}\text { In FMS compared to controls: } \\
\text { IL-1 } 1 \beta, \text { IL-2, IL-6, IL-8, IL-10, ILIL-2R, IFN } \gamma \text {, } \\
\text { TNF: } \leftrightarrow \text { in sera +PBMC } \\
\text { IL-1RA: } \Uparrow \text { in serum } \\
\text { IL-8: } \Uparrow \text { in plasma IL-1 RA, IL-6: } \Uparrow \text { in } \\
\text { PBMC } \\
\text { IL-6: } \Uparrow \text { in PBMC of patients with } \\
\text { disease duration > } 2 \text { years. }\end{array}$ & $3 d$ & 3 & 0.5 \\
\hline $\begin{array}{l}\text { Gür, } 2002 \\
\text { ACR }\end{array}$ & $81 / 32$ & $\begin{array}{l}\text { a) serum } \\
\text { b) ELISA } \\
\text { c) IL-1, IL-2R, IL-6, IL-8 }\end{array}$ & $\begin{array}{l}\text { In FMS compared to controls: } \\
\mathrm{IL}-1 \leftrightarrow \\
\mathrm{IL}-2 \mathrm{R} \Uparrow \\
\mathrm{IL}-6 \leftrightarrow \\
\mathrm{IL}-8 \Uparrow\end{array}$ & $3 d$ & 2 & 0.4 \\
\hline $\begin{array}{l}\text { Schwarz, } \\
2002 \\
\text { ACR } \\
\end{array}$ & $17 / 17$ & $\begin{array}{l}\text { a) serum } \\
\text { b) ELISA } \\
\text { c) IL-6 }\end{array}$ & $\begin{array}{l}\text { IL-6 } \Uparrow \text { during tryptophan depletion in } \\
\text { FMS }\end{array}$ & $3 d$ & 4 & 0.3 \\
\hline $\begin{array}{l}\text { Amel } \\
\text { Kashipaz, } \\
2003 \\
\text { ACR }\end{array}$ & $22 \mathrm{FMS} / \mathrm{CFS} / 19$ & $\begin{array}{l}\text { a) PBMC } \\
\text { b) intracellular cytokine stain; flow } \\
\text { cytometry } \\
\text { c) IL-1 } \alpha, I L-6, I L-10, T N F\end{array}$ & $\begin{array}{l}\text { In FMS compared to controls: } \\
\text { IL-1 } \alpha \leftrightarrow \\
\text { IL- } 6 \leftrightarrow \\
\text { IL-10↔ } \\
\text { TNF } \leftrightarrow \\
\end{array}$ & $3 d$ & 2 & 0.7 \\
\hline $\begin{array}{l}\text { Salemi, } \\
2003 \\
\text { ACR }\end{array}$ & $53 / 10$ & $\begin{array}{l}\text { a) skin biopsy } \\
\text { b) RT-PCR, IHC } \\
\text { c) IL-1 } \beta, I L-6, \text { TNF }\end{array}$ & $\begin{array}{l}\text { Detectable cytokines in FMS: } \\
\text { IL-1 } 1 \text { (19/50) } \\
\text { IL-6 }(14 / 51) \\
\text { TNF }(17 / 53) \\
\text { None of the cytokines could be } \\
\text { detected in control skin. }\end{array}$ & $3 d$ & 2 & 0.7 \\
\hline $\begin{array}{l}\text { Ardic, } 2006 \\
\text { ACR }\end{array}$ & $21 / 10$ & $\begin{array}{l}\text { a) serum } \\
\text { b) ELISA } \\
\text { c) IL-1 (after balneo therapy) }\end{array}$ & $\begin{array}{l}\text { After balneo therapy: } \\
\text { IL-1 } \downarrow \text { in FMS }\end{array}$ & $3 d$ & 3 & 0.2 \\
\hline $\begin{array}{l}\text { Üçeyler, } \\
2006 \\
\text { ACR }\end{array}$ & $26 / 40$ & $\begin{array}{l}\text { a) serum; whole blood } \\
\text { b) qRT-PCR; } \\
\text { ELISA } \\
\text { c) IL-2, IL-4, IL-8, IL-10, TNF, TGF- } \beta 1\end{array}$ & $\begin{array}{l}\text { In FMS compared to controls: } \\
\text { IL-2 } \\
\text { IL-4 } \Downarrow \\
\text { IL-8 } \\
\text { IL-10 } \Downarrow \\
\text { TGF- } \beta 1 \leftrightarrow \\
\text { TNF } \leftrightarrow\end{array}$ & $3 d$ & 4 & 0.8 \\
\hline
\end{tabular}


Table 3 Characteristics of all studies included in the systematic review investigating cytokines in FMS patients. (Continued)

\begin{tabular}{|c|c|c|c|c|c|c|}
\hline $\begin{array}{l}\text { Bazzichi, } \\
2007 \\
\text { ACR }\end{array}$ & $\begin{array}{l}\text { 285/40 ( } 16 \text { rheumatoid } \\
\text { arthritis cases, two Sjögren's } \\
\text { syndrome cases, } 16 \\
\text { systemic lupus } \\
\text { erythematosus cases, } \\
\text { four systemic sclerosis cases, } \\
\text { two undifferentiated } \\
\text { connective- } \\
\text { tissue disease cases)/100 }\end{array}$ & $\begin{array}{l}\text { a) serum, plasma } \\
\text { b) ELISA } \\
\text { c) IL-1, IL-6, IL-8, IL-10, TNF } \alpha\end{array}$ & No intergroup difference for cytokines. & $3 d$ & 3 & 0.2 \\
\hline $\begin{array}{l}\text { Bazzichi, } \\
2007 \\
\text { ACR }\end{array}$ & $80 / 45$ & $\begin{array}{l}\text { a) plasma } \\
\text { b) ELISA } \\
\text { c) IL-1, IL-6, IL-8, IL-10, TNF }\end{array}$ & IL-10, IL-8, TNF: FMS > controls & $3 c$ & 3 & 0.9 \\
\hline $\begin{array}{l}\text { Macedo, } \\
2007 \\
\text { ACR }\end{array}$ & $18 / 22$ & $\begin{array}{l}\text { a) PBMC } \\
\text { b) automated biochip array; before } \\
\text { and after } 1.5 \mathrm{mg} \text { of dexamethasone } \\
\text { per os } \\
\text { c) IL-1 } \alpha, I L-1 \beta, I L-2, I L-4, I L-6, I L-8, I L- \\
10 \text {, IFN } \gamma_{\text {, TNF }}\end{array}$ & $\begin{array}{l}\text { After dexamethasone: reduction of } \\
\text { cytokines FMS > controls. }\end{array}$ & $3 d$ & 2 & 0.4 \\
\hline $\begin{array}{l}\text { Kaufmann, } \\
2007 \\
\text { ACR }\end{array}$ & 22/15 CRPS/37 & $\begin{array}{l}\text { a) T-cells } \\
\text { b) FACS analysis } \\
\text { c) IL-2, IFN }, \text { IL-4, IL-10 }\end{array}$ & $\begin{array}{l}\text { No difference in percentage of } \\
\text { cytokine producing cells between } \\
\text { FMS and controls. }\end{array}$ & $3 d$ & 2 & 0.6 \\
\hline $\begin{array}{l}\text { Togo, } \\
2008 \\
\text { ACR }\end{array}$ & $7 / 9$ & $\begin{array}{l}\text { a) plasma } \\
\text { b) Beadlyte multi-cytokine assay } \\
\text { c) IL-10, IL-6, IL-8, IL-1, TNF }\end{array}$ & $\begin{array}{l}\text { No difference between groups. } \\
\text { "FM patients showed a shift to } \\
\text { increased IL-10 in the } \\
\text { nighttime compared to controls." }\end{array}$ & $3 d$ & 2 & 0.8 \\
\hline $\begin{array}{l}\text { Wang, } 2008 \\
\text { ACR }\end{array}$ & $20 / 80$ & $\begin{array}{l}\text { a) serum } \\
\text { b) Bio-Plex cytokine assay } \\
\text { c) IL-6, IL-8, IL-10, IL-4, TNF }\end{array}$ & $\begin{array}{l}\text { At baseline: IL-8 in FMS > controls; no } \\
\text { difference for other cytokines. }\end{array}$ & $3 d$ & 4 & 0.4 \\
\hline $\begin{array}{l}\text { Zhang, } \\
2008 \\
\text { ACR }\end{array}$ & $\begin{array}{l}\text { 92/69 family members } / 62 \\
\text { anonymous blood samples } \\
\text { from blood bank }\end{array}$ & $\begin{array}{l}\text { a) plasma } \\
\text { b) Cytokine Twenty-Five-Plex } \\
\text { Antibody Bead Kit } \\
\text { c) MCP-1, Eotaxin, IP-10, IL-13, IL-5, IL- } \\
\text { 10, IL-1b, IL-2, IL-4, IL-6, IL-7, IL-8, IL- } \\
\text { 12, IL-15, IL-17, TNF, IFNa, IFNg, GM- } \\
\text { CSF, MIG, MIP-1a, MIP-1b, IL-1ra, IL-2r }\end{array}$ & Eotaxin and MIP: FMS > controls & $3 d$ & 3 & 0.5 \\
\hline $\begin{array}{l}\text { Feng, } 2009 \\
\text { ACR }\end{array}$ & $\begin{array}{l}100 \text { FMS patients and family } \\
\text { members/35 unaffected } \\
\text { parents }\end{array}$ & $\begin{array}{l}\text { a) plasma } \\
\text { b) Cytokine Twenty-Five-Plex } \\
\text { Antibody Bead Kit } \\
\text { c) Eotaxin, MIP.1a, MCP-1, IP10, IL-12, } \\
\text { IL-1 } \beta\end{array}$ & $\begin{array}{l}\text { Rare missense variants of the MEFV } \\
\text { gene are associated with risk of FMS } \\
\text { and are present in a subset of 15\% of } \\
\text { FMS patients. This subset had, on } \\
\text { average, high levels of plasma IL-1b } \\
\text { compared to FMS patients without } \\
\text { rare variants, unaffected family } \\
\text { members with or without rare } \\
\text { variants, and unrelated controls of } \\
\text { unknown genotype. }\end{array}$ & $3 d$ & 3 & 0.4 \\
\hline $\begin{array}{l}\text { Blanco, } \\
2010 \\
\text { ACR }\end{array}$ & $63 / 49$ & $\begin{array}{l}\text { a) skin } \\
\text { b) immuno-histochemistry } \\
\text { c) MCP-1, TNF }\end{array}$ & MCP-1: FMS < controls & $3 c$ & 3 & 0.8 \\
\hline $\begin{array}{l}\text { Blanco, } \\
2010 \\
\text { ACR }\end{array}$ & $79 / 59$ & $\begin{array}{l}\text { a) plasma } \\
\text { b) sandwich enzyme immunoassay } \\
\text { kits } \\
\text { c) IL-8, TNF, sTNF-RI, sTNF-RII, MCP-1 }\end{array}$ & $\begin{array}{l}\text { Patients with FMS have lower } \\
\text { systemic levels of MCP-2 than } \\
\text { controls. }\end{array}$ & $3 d$ & 3 & 0.4 \\
\hline $\begin{array}{l}\text { Hernandez, } \\
2010 \\
\text { ACR }\end{array}$ & $64 / 25$ & $\begin{array}{l}\text { a) serum } \\
\text { b) ELISA } \\
\text { c) TNF, IL-1, IL-6 }\end{array}$ & $\begin{array}{l}\text { TNF: FMS < controls } \\
\text { IL-1: not detectable in FMS } \\
\text { IL-6: FMS > controls }\end{array}$ & $3 c$ & 4 & 0.6 \\
\hline $\begin{array}{l}\text { lannucelli, } \\
2010 \\
\text { ACR }\end{array}$ & $\begin{array}{l}\text { 51/25 tension type } \\
\text { headache/15 }\end{array}$ & $\begin{array}{l}\text { a) serum } \\
\text { b) multiplex bead-based sandwich } \\
\text { immunoassay } \\
\text { c) IL-1 } \beta, \text { IL-1R } \alpha, I L-4, I L-6, I L-8, I L-10 \text {, } \\
\text { INF } \gamma \text {, TNF }\end{array}$ & FMS > controls: IL-1RA, IL-6, IL-10, TNF & $3 d$ & 3 & 0.7 \\
\hline
\end{tabular}


Table 3 Characteristics of all studies included in the systematic review investigating cytokines in FMS patients. (Continued)

\begin{tabular}{|c|c|c|c|c|c|c|}
\hline $\begin{array}{l}\text { Ortega, } \\
2010 \\
\text { ACR }\end{array}$ & $9 / 9$ & $\begin{array}{l}\text { a) PBMC } \\
\text { b) ELISA } \\
\text { c) IL-1 } 1 \beta, T N F, I L-6, I L-10\end{array}$ & $\begin{array}{l}\text { For all cytokines investigated: higher } \\
\text { values at baseline in FMS compared } \\
\text { to controls; after aquatic exercise } \\
\text { levels as in controls. }\end{array}$ & $3 d$ & 3 & 0.3 \\
\hline $\begin{array}{l}\text { Ross, } 2010 \\
\text { ACR }\end{array}$ & 24/none & $\begin{array}{l}\text { a) serum } \\
\text { b) bead-based immunofluorescence } \\
\text { assay } \\
\text { c) IL-1 } \alpha, I L-1 \beta, I L-1 R A, I L-6, I L-8, I L-10 \text {, } \\
\text { TNF }\end{array}$ & $\begin{array}{l}\mathrm{IL}-6 \text { and } \mathrm{IL}-8 \text { : FMS responders (i.e. GH } \\
\text { response to exercise of } \geq 5 \mathrm{ng} / \mathrm{mL} \text { ) } \\
\text { higher than FMS non-responders. For } \\
\mathrm{IL}-1 \alpha \text { vice versa. }\end{array}$ & 4 & 1 & 0.2 \\
\hline
\end{tabular}

Abbreviations:

ACR: American College of Rheumatology; CEMB: Center of Evidence Based Medicine; ELISA: enzyme linked immunosorbent assay; FMS: fibromyalgia syndrome; IL: interleukin; NOS: Newcastle Ottawa Scale; NR: not reported; PBMC: peripheral blood mononuclear cells; qRT-PCR: quantitative real-time PCR; R: receptor; RA: receptor antagonist; W-MeQS: Würzburg Methodological Quality Score; yrs: years

$[17,20,26,29,33]$, with FACS analysis in two studies $[10,21]$, with quantitative real-time PCR in one study [30], with reverse transcription PCR in one study [27], with immunohistochemistry in one study [15].

There is little overlap in materials and methods used between different studies investigating cytokine levels in FMS patients.

\section{Systematic review \\ Serum (Table 4)}

Serum samples of 643 FMS patients, 109 patients in disease control groups, and 301 healthy controls were investigated. Only one study reached a modified CEMB level of 3c [19]; ten studies had a modified CEMB level of $3 d$ [11,13,20,23,25,28,30-32,34]; one study had a modified CEMB level of 4 [26]. Four studies had a NOS score of $4[19,28,30,32]$, five studies had a NOS score of $3[11,13,20,25,31]$, two studies had a NOS score of 2 $[23,34]$, and one study of 1 [26]. Applying W-MeQS only one study was of high methodological quality [30]; three studies were of medium quality $[19,20,31]$, and eight studies of low methodological quality $[11,13,23,25,26,28,32,34]$.

The following results were reproduced (regardless of the method used and with a minimum of two independent studies): patients with FMS have higher serum levels of IL-1RA [20,23,31], IL-6 [19,20,28], and IL-8 $[32,34]$. No intergroup difference was found for serum IL-6 $[13,23,25,31,32,34]$, IL-1 $\beta /$ IL-1 $[13,20,25,31,34]$, TNF [13,25,30-32], IL-2 [30,31], IL-10 [13,31,32], IFN- $\gamma$ [20,31], IL-4 [20,32].

Discrepant results are described for IL-6: IL-6 levels were found higher in FMS patients compared to controls in three studies $[19,20,28] ; 2 / 3$ studies were of medium methodological quality $[19,20], 2 / 3$ studies had a NOS score of $4[19,28]$, and $1 / 3$ study had a modified CEBM of 3c [19]. In six studies no intergroup difference could be found for serum IL-6 levels [13,23,25,31,32,34]; $5 / 6$ studies were of low methodological quality
$[13,23,25,32,34]$, only $1 / 6$ studies reached a NOS score of 4 [32], and 6/6 studies had a modified CEBM level of 3d $[13,23,25,31,32,34]$. The better quality of studies showing elevated serum IL-6 levels in FMS patients compared to controls favors this finding, although in more studies (with less quality) no intergroup difference could be found.

The majority of studies were of low methodological quality and there was hardly an overlap in the methods used and the cytokines investigated. Only IL-1RA, IL-6, and IL- 8 were higher expressed in sera of FMS patients, while for all other cytokines no intergroup difference could be found.

\section{Plasma (Table 5)}

Plasma cytokine levels were investigated in seven studies $[13,14,16,17,29,31,33]$.

Plasma samples of 699 FMS patients, 109 patients in disease control groups, and 357 healthy controls were investigated. Only one study reached a modified CEMB level of 3c [14]; six studies had a modified CEMB level of $3 d[13,16,17,29,31,33]$. Six studies had a NOS score of $3[13,14,16,17,31,33]$, one study of 2 [29]. Applying WMeQS only two studies were of high methodological quality $[14,29]$, two studies were of medium $[31,33]$, and two studies of low methodological quality $[16,17]$.

The following results were reproduced (regardless of the method used and with a minimum of two independent studies): patients with FMS have higher plasma levels of IL-8 [14,31]. No intergroup difference was found for plasma IL-1 $\beta /$ IL-1 [13,14,17,29,31,33], IL-6 $[13,14,29,31,33], \quad$ IL-8 $\quad[13,16,29,33], \quad$ TNF $[13,16,29,31,33]$, and IL-10 [13,29,31,33], MCP-1 and IP10 [17,33], IL-2 and IFN- $\gamma[31,33]$.

Discrepant results are described for IL-8: IL-8 levels were found higher in FMS patients compared to controls in two studies [14,31]; $1 / 2$ studies was of medium [31] and $1 / 2$ studies was of high methodological quality [14], both studies had a NOS score of 3, and one study reached a modified CEBM level of 3c [14]. In four 
Table 4 Characteristics of studies investigating serum levels of cytokines in FMS patients.

\begin{tabular}{|c|c|c|c|c|c|c|}
\hline $\begin{array}{l}\text { Author, yr. } \\
\text { Diagnosis } \\
\text { criteria }\end{array}$ & $\mathrm{N}$ patients/controls & $\begin{array}{l}\text { a) Material } \\
\text { b) Methods } \\
\text { c) Investigated } \\
\text { targets }\end{array}$ & Results & $\begin{array}{l}\text { Modified } \\
\text { CEBM } \\
\text { level }\end{array}$ & NOS & $\begin{array}{l}\text { W- } \\
\text { MeQS }\end{array}$ \\
\hline $\begin{array}{l}\text { Maes, } 1999 \\
\text { ACR }\end{array}$ & $21 / 33$ & $\begin{array}{l}\text { a) serum } \\
\text { B) ELISA } \\
\text { c) IL-6, sIL-6 R, sIL-1R, } \\
\text { IL-1 RA }\end{array}$ & $\begin{array}{l}\text { In FMS compared to controls: } \\
\text { IL-6↔ } \\
\text { SIL-6R } \Uparrow \\
\text { SIL-1R } \Uparrow \\
\text { IL-1 RA } \Uparrow\end{array}$ & $3 d$ & 2 & 0.3 \\
\hline $\begin{array}{l}\text { Pay. } 2000 \\
\text { ACR }\end{array}$ & $\begin{array}{l}25 \mathrm{FMS} / 25 \text { chronic } \\
\text { musculoskeletal } \\
\text { complaints/25 controls }\end{array}$ & $\begin{array}{l}\text { a) serum } \\
\text { b) ELISA } \\
\text { c) IL-1b, TNF, IL-6 }\end{array}$ & $\begin{array}{l}\text { No difference for pro-inflammatory cytokines in FMS } \\
\text { and controls. }\end{array}$ & $3 d$ & 3 & 0.4 \\
\hline $\begin{array}{l}\text { Wallace, } \\
2001 \\
\text { ACR }\end{array}$ & $56 / 56$ & $\begin{array}{l}\text { a) serum, PBMC, } \\
\text { plasma } \\
\text { b) ELISA } \\
\text { c) IL-1 } 13, \text { IL-2, IL-6, IL-8, } \\
\text { IL-10, sIL-2 R, IL-1 RA, } \\
\text { IFN } \gamma \text {, TNF }\end{array}$ & $\begin{array}{l}\text { In FMS compared to controls: } \\
\text { IL-1 } 1 \beta, \text { IL-2, IL-6, IL-8, IL-10, sIL-2 R, IFN } \gamma, T N F: \leftrightarrow \text { in sera } \\
+ \text { PBMC } \\
\text { IL-1 RA: } \Uparrow \text { in serum } \\
\text { IL-8: } \Uparrow \text { in plasma } \\
\text { IL-1 RA, IL-6: } \Uparrow \text { in PBMC } \\
\text { IL-6: } \Uparrow \text { in PBMC of patients with disease duration }>2 \\
\text { years. }\end{array}$ & $3 d$ & 3 & 0.5 \\
\hline $\begin{array}{l}\text { Gür, } \\
2002 \\
\text { ACR }\end{array}$ & $81 / 32$ & $\begin{array}{l}\text { a) serum } \\
\text { b) ELISA } \\
\text { c) } I L-1, I L-2 R, \| L-6 \text {, } \\
\text { IL-8 }\end{array}$ & $\begin{array}{l}\text { In FMS compared to controls: } \\
\mathrm{IL}-1 \leftrightarrow \\
\mathrm{IL}-2 \mathrm{R} \Uparrow \\
\mathrm{IL}-6 \leftrightarrow \\
\mathrm{IL}-8 \Uparrow\end{array}$ & $3 d$ & 2 & 0.4 \\
\hline $\begin{array}{l}\text { Schwarz, } \\
2002 \\
\text { ACR } \\
\end{array}$ & $17 / 17$ & $\begin{array}{l}\text { a) serum } \\
\text { b) ELISA } \\
\text { c) IL-6 }\end{array}$ & IL-6 $\Uparrow$ during tryptophan depletion in FMS & $3 d$ & 4 & 0.3 \\
\hline $\begin{array}{l}\text { Ardic, } 2006 \\
\text { ACR }\end{array}$ & 21/10 (data not given) & $\begin{array}{l}\text { a) serum } \\
\text { b) ELISA } \\
\text { c) IL-1 (after balneo } \\
\text { therapy) }\end{array}$ & $\begin{array}{l}\text { After balneo therapy: } \\
\text { IL-1 } \downarrow \text { in FMS }\end{array}$ & $3 d$ & 3 & 0.2 \\
\hline $\begin{array}{l}\text { Üçeyler, } \\
2006 \\
\text { ACR }\end{array}$ & $26 / 40$ & $\begin{array}{l}\text { a) serum; whole blood } \\
\text { b) qRT-PCR; } \\
\text { ELISA } \\
\text { c) IL-2, IL-4, IL-8, IL-10, } \\
\text { TNF, TGF } \beta 1\end{array}$ & $\begin{array}{l}\text { In FMS compared to controls: } \\
\text { IL-2 } \\
\text { IL-4 } \Downarrow \\
\text { IL-8 } \leftrightarrow \\
\text { IL-10 } \\
\text { TGF } \beta 1 \leftrightarrow \\
\text { TNF } \leftrightarrow\end{array}$ & $3 d$ & 4 & 0.8 \\
\hline $\begin{array}{l}\text { Bazzichi, } \\
2007 \\
\text { ACR }\end{array}$ & $\begin{array}{l}\text { 285/40 (16 rheumatoid } \\
\text { arthritis cases, two } \\
\text { Sjögren's } \\
\text { syndrome cases, } 16 \\
\text { systemic lupus } \\
\text { erythematosus cases, } \\
\text { four systemic sclerosis } \\
\text { cases, two undifferentiated } \\
\text { connective- } \\
\text { tissue disease cases)/100 }\end{array}$ & $\begin{array}{l}\text { a) serum, plasma } \\
\text { b) ELISA } \\
\text { c) IL-1, IL-6, IL-8, IL-10, } \\
\text { TNF }\end{array}$ & No intergroup difference for cytokines. & $3 d$ & 3 & 0.2 \\
\hline $\begin{array}{l}\text { Wang, } 2008 \\
\text { ACR }\end{array}$ & $20 / 80$ & $\begin{array}{l}\text { a) serum } \\
\text { b) Bio-Plex cytokine } \\
\text { assay } \\
\text { c) IL-6, IL-8, IL-10, IL-4, } \\
\text { TNF } \\
\end{array}$ & $\begin{array}{l}\text { At baseline: IL-8 in FMS > controls; no difference for } \\
\text { other cytokines. }\end{array}$ & $3 d$ & 4 & 0.4 \\
\hline $\begin{array}{l}\text { Hernandez, } \\
2010 \\
\text { ACR } \\
\end{array}$ & $64 / 25$ & $\begin{array}{l}\text { a) serum } \\
\text { b) ELISA } \\
\text { c) TNF, IL-1, IL-6 }\end{array}$ & $\begin{array}{l}\text { TNF: FMS < controls } \\
\text { IL-1: not detectable in FMS } \\
\text { IL-6: FMS > controls }\end{array}$ & $3 c$ & 4 & 0.6 \\
\hline $\begin{array}{l}\text { lannucelli, } \\
2010 \\
\text { ACR }\end{array}$ & $\begin{array}{l}\text { 51/25 tension type } \\
\text { headache/15 }\end{array}$ & $\begin{array}{l}\text { a) serum } \\
\text { b) multiplex bead- } \\
\text { based sandwich } \\
\text { immunoassay } \\
\text { c) IL-1b, IL-1Ra, IL-4, IL- } \\
6 \text {, IL-8, IL-10, INFy, TNF }\end{array}$ & FMS > controls: IL-1Ra, IL-6, IL-10, TNF & $3 d$ & 3 & 0.7 \\
\hline
\end{tabular}


Table 4 Characteristics of studies investigating serum levels of cytokines in FMS patients. (Continued)

\begin{tabular}{|c|c|c|c|c|c|c|}
\hline $\begin{array}{l}\text { Ross, } 2010 \\
\text { ACR }\end{array}$ & 24/none & $\begin{array}{l}\text { a) serum } \\
\text { b) bead-based } \\
\text { immunofluorescence } \\
\text { assay } \\
\text { c) IL-1a, IL-1b, IL-1RA, } \\
\text { IL-6, IL-8, IL-10, TNF }\end{array}$ & $\begin{array}{l}\mathrm{IL}-6 \text { and } \mathrm{IL}-8 \text { : FMS responders (i.e. GH response to } \\
\text { exercise of } \geq 5 \mathrm{ng} / \mathrm{mL} \text { ) higher than FMS non- } \\
\text { responders. For } \mathrm{IL}-1 \mathrm{a} \text { vice versa. }\end{array}$ & 4 & 1 & 0.2 \\
\hline
\end{tabular}

FMS > controls

IL-1 RA: lannuccelli 2010; Maes, 1999; Wallace 2001

IL-6: Iannucelli, 2010; Schwarz, 2002; Hernandez, 2010

IL-8: Gür, 2002; Wang, 2008

FMS $=$ controls

IL-6: Maes, 1999; Pay, 2000; Wallace, 2001; Gür, 2002b; Bazzichi, 2007; Wang 2008

IL-1b/IL-1: Pay, 2000; Wallace, 2001; Gür, 2002b; Bazzichi, 2007; lannucelli, 2010

TNF: Pay, 2000; Wallace, 2001; Bazzichi, 2007; Wang, 2008

IL-2: Wallace, 2001; Üçeyler, 2006

IL-10: Wallace, 2001; Bazzichi, 2007; Wang, 2008

IFN-g: Wallace, 2001; lannucelli, 2010

IL-4: Wang, 2008; lannucelli, 2010

Abbreviations:

ACR: American College of Rheumatology; CEMB: Center of Evidence Based Medicine; ELISA: enzyme linked immunosorbent assay; FMS: fibromyalgia syndrome; IL: interleukin; KYN: kynurenine; NOS: Newcastle Ottawa Scale; NR: not reported; PBMC: peripheral blood mononuclear cells; qRT-PCR: quantitative real-time PCR; R: receptor; RA: receptor antagonist; W-MeQS: Würzburg Methodological Quality Score; yr: year

studies no intergroup difference could be found for plasma IL-8 levels [13,16,29,33]; 2/4 studies were of low methodological quality $[13,16]$ and $3 / 4$ studies had a NOS score of $3[13,16,33]$; the only study with high methodological quality had a NOS score of only 2 [29]; all four studies had a modified CEBM level of 3d. The better quality of studies showing elevated plasma IL-8 levels in FMS patients compared to controls favors this finding, although in more studies (with less quality) no intergroup difference could be found.

The majority of studies were of low methodological quality with only little overlap in methodology and cytokines investigated. A difference between FMS patients and controls was found only for IL-8 plasma levels. When taking studies investigating serum and plasma together we found no intergroup difference.

\section{Whole blood (Table 6)}

Cytokine expression in whole blood of patients with FMS was investigated in one study including 26 FMS patients and 40 healthy controls [30]. The study had a modified CEMB level of 3d, a NOS of 4 and was of high methodological quality and found reduced levels of the anti-inflammatory cytokines IL-4 and IL-10 gene expression in FMS patients compared to controls. These results were not reproduced.

\section{Peripheral blood mononuclear cells (Table 7)}

Cytokine expression in peripheral blood mononuclear cells (PBMC) was investigated in seven studies [10,12,18,21,22,24,31].

PBMC of 151 FMS patients, 21 patients in disease control groups, and 159 healthy controls were investigated. All seven studies had a modified CEMB level of $3 d[10,12,18,21,22,24,31]$. One study reached a NOS score of 4 [12], two studies of 3 [24,31], and four studies of $2[10,18,21,22]$. Applying W-MeQS three studies were of medium methodological quality $[10,21,31]$ and four were of low quality $[12,18,22,24]$.

The following results were reproduced (regardless of the method used and with a minimum of two independent studies): no intergroup difference was found for IL-10 secretion from PBMC between FMS patients and controls [10,22,31].

FMS patients do not differ in PBMC cytokine levels from healthy controls.

\section{Skin (Table 8)}

Cytokine expression in skin of FMS patients was investigated in two studies including 116 FMS patients, and 59 healthy controls $[15,27]$. One study had a modified CEMB level of 3c [15] and one of 3d [27]; one study had a NOS score of 3 [16], the other of 2 [27]. Applying W-MeQS one study was of high methodological quality [16], one study of medium quality [27]. In the study by Salemi et al. [27] IL-1 $\beta$, IL-6, and TNF were detectable in skin samples of a subgroup of FMS patients using reverse transcription PCR and immunohistochemistry, while in controls none of these cytokines could be detected. Blanco et al. [15] investigated TNF and MCP1 in skin biopsies using immunohistochemistry and found lower MCP-1 expression in FMS patients than in controls. None of the results were reproduced.

\section{Meta-analysis}

In the selected 16 papers for meta-analysis authors investigated different cytokines with various methods. We therefore created subgroups of papers that investigated the same cytokine with the same or a comparable 
Table 5 Characteristics of studies investigating plasma levels of cytokines in FMS patients.

\begin{tabular}{|c|c|c|c|c|c|c|}
\hline $\begin{array}{l}\text { Author, } \\
\text { yr. } \\
\text { Diagnosis } \\
\text { criteria }\end{array}$ & $\begin{array}{l}\text { N patients/ } \\
\text { controls }\end{array}$ & $\begin{array}{l}\text { a) Material } \\
\text { b) Methods } \\
\text { c) Investigated targets }\end{array}$ & Results & $\begin{array}{l}\text { Modified } \\
\text { CEBM } \\
\text { level }\end{array}$ & NOS & $\begin{array}{l}\text { W- } \\
\text { MeQS }\end{array}$ \\
\hline $\begin{array}{l}\text { Wallace, } \\
2001 \\
\text { ACR }\end{array}$ & $56 / 56$ & $\begin{array}{l}\text { a) serum, PBMC, plasma } \\
\text { b) ELISA } \\
\text { c) IL-1 } 1 \text {, IL-2, IL-6, IL-8, IL-10, SIL-2R, IL-1RA, } \\
\text { IFN } \gamma \text {, TNF }\end{array}$ & $\begin{array}{l}\text { In FMS compared to controls: } \\
\text { IL-1 } \beta, \text { IL-2, IL-6, IL-8, IL-10, sIL-2R, IFN } \gamma \text {, } \\
\text { TNF: } \leftrightarrow \text { in sera +PBMC } \\
\text { IL-1RA: } \Uparrow \text { in serum } \\
\text { IL-8: } \Uparrow \text { in plasma } \\
\text { IL-1RA, IL-6: } \Uparrow \text { in PBMC } \\
\text { IL-6: } \Uparrow \text { in PBMC of patients with disease } \\
\text { duration }>2 \text { years. }\end{array}$ & $3 d$ & 3 & 0.5 \\
\hline $\begin{array}{l}\text { Bazzichi, } \\
2007 \\
\text { ACR }\end{array}$ & $\begin{array}{l}\text { 285/40 (16 } \\
\text { rheumatoid arthritis } \\
\text { cases, two Sjögren's } \\
\text { syndrome cases, } 16 \\
\text { systemic lupus } \\
\text { erythematosus } \\
\text { cases, } \\
\text { four systemic } \\
\text { sclerosis cases, two } \\
\text { undifferentiated } \\
\text { connective- } \\
\text { tissue disease } \\
\text { cases)/100 }\end{array}$ & $\begin{array}{l}\text { a) serum, plasma } \\
\text { b) ELISA } \\
\text { c) IL-1, IL-6, IL-8, IL-10, TNF }\end{array}$ & No intergroup difference for cytokines. & $3 d$ & 3 & 0.2 \\
\hline $\begin{array}{l}\text { Bazzichi, } \\
2007 \\
\text { ACR }\end{array}$ & $80 / 45$ & $\begin{array}{l}\text { a) plasma } \\
\text { b) ELISA } \\
\text { c) IL-1, IL-6, IL-8, IL-10, TNF }\end{array}$ & IL-10, IL-8, TNF: FMS > controls & $3 c$ & 3 & 0.9 \\
\hline $\begin{array}{l}\text { Togo, } \\
2008 \\
\text { ACR }\end{array}$ & $7 / 9$ & $\begin{array}{l}\text { a) plasma } \\
\text { b) Beadlyte multi-cytokine assay } \\
\text { c) IL-10, IL-6, IL-8, IL-1, TNF }\end{array}$ & No difference between groups. & $3 d$ & 2 & 0.8 \\
\hline $\begin{array}{l}\text { Zhang, } \\
2008 \\
\text { ACR }\end{array}$ & $\begin{array}{l}\text { 92/69 family } \\
\text { members/62 } \\
\text { anonymous blood } \\
\text { samples from blood } \\
\text { bank }\end{array}$ & $\begin{array}{l}\text { a) plasma } \\
\text { b) Cytokine Twenty-Five-Plex Antibody } \\
\text { Bead Kit } \\
\text { c) MCP-1, Eotaxin, IP-10, IL-13, IL-5, IL-10, } \\
\text { IL-1 } \beta, \text { IL-2, IL-4, IL-6, IL-7, IL-8, IL-12, IL-15, } \\
\text { IL-17, TNF, IFN } \alpha, I F N \gamma, \text { GM-CSF, MIG, MIP- } \\
1 \alpha, M I P-1 \beta, I L-1 R A, I L-2 R\end{array}$ & Eotaxin and MIP: FMS > controls & $3 d$ & 3 & 0.5 \\
\hline $\begin{array}{l}\text { Feng, } \\
2009 \\
\text { ACR }\end{array}$ & $\begin{array}{l}100 \text { FMS patients } \\
\text { and family } \\
\text { members/35 } \\
\text { unaffected parents }\end{array}$ & $\begin{array}{l}\text { a) plasma } \\
\text { b) Cytokine Twenty-Five-Plex Antibody } \\
\text { Bead Kit } \\
\text { c) Eotaxin, MIP-1 } \alpha, \text { MCP-1, IP10, IL-12, IL- } \\
1 \beta\end{array}$ & $\begin{array}{l}\text { Rare missense variants of the MEFV gene } \\
\text { are associated with risk of FMS and are } \\
\text { present in a subset of } 15 \% \text { of FMS } \\
\text { patients. This subset had, on average, } \\
\text { high levels of plasma IL-1b compared to } \\
\text { FMS patients without rare variants, } \\
\text { unaffected family members with or } \\
\text { without rare variants, and unrelated } \\
\text { controls of unknown genotype. }\end{array}$ & $3 d$ & 3 & 0.4 \\
\hline $\begin{array}{l}\text { Blanco, } \\
2010 \\
\text { ACR }\end{array}$ & $79 / 59$ & $\begin{array}{l}\text { a) plasma } \\
\text { b) sandwich enzyme immunoassay kits } \\
\text { c) IL-8, TNF, sTNF-RI, sTNF-RII, MCP-1 }\end{array}$ & $\begin{array}{l}\text { Patients with FMS have lower systemic } \\
\text { levels of MCP-2 than controls. }\end{array}$ & $3 d$ & 3 & 0.4 \\
\hline
\end{tabular}

FMS > controls

IL-8: Bazzichi, 2007b; Wallace, 2001

FMS $=$ controls

IL-1B/IL-1: Wallance, 2001; Bazzichi, 2007a and b; Zhang, 2008; Feng, 2009; Togo, 2009

IL-6: Wallance, 2001; Bazzichi, 2007a; Bazzichi, 2007a and b; Zhang, 2008; Togo, 2009

IL-8: Bazzichi, 2007a; Zhang, 2008; Togo, 2009; Blanco, 2010b

TNF: Wallance, 2001; Bazzichi, 2007a; Zhang, 2008; Togo, 2009; Blanco, 2010b

IL-10: Wallace, 2001; Bazzichi, 2007a; Zhang, 2008; Togo, 2009

MCP-1 and IP10: Zhang, 2001;Feng 2009

IL-2: Wallace, 2001; Zhang, 2008

IFN $\gamma$ : Wallace, 2001; Zhang, 2008

Abbreviations:

ACR: American College of Rheumatology; CEMB: Center of Evidence Based Medicine; ELISA: enzyme linked immunosorbent assay; FMS: fibromyalgia syndrome; IL: interleukin; NOS: Newcastle Ottawa Scale; NR: not reported; PBMC: peripheral blood mononuclear cells; R: receptor; RA: receptor antagonist; W-MeQS: Würzburg Methodological Quality Score; yr: year 
Table 6 Characteristics of studies investigating whole blood levels of cytokines in FMS patients.

\begin{tabular}{|c|c|c|c|c|c|c|}
\hline $\begin{array}{l}\text { Author, yr. } \\
\text { Diagnosis criteria }\end{array}$ & $\mathrm{N}$ patients/controls & $\begin{array}{l}\text { a) Material } \\
\text { b) Methods } \\
\text { c) Investigated targets }\end{array}$ & Results & $\begin{array}{l}\text { Modified CEBM } \\
\text { level }\end{array}$ & NOS & W-MeQS \\
\hline $\begin{array}{l}\text { Üçeyler, } 2006 \\
\text { ACR }\end{array}$ & $26 / 40$ & $\begin{array}{l}\text { a) serum; whole blood } \\
\text { b) qRT-PCR; } \\
\text { ELISA } \\
\text { c) IL-2, IL-4, IL-8, IL-10, TNF, TGF- } \beta 1\end{array}$ & $\begin{array}{l}\text { In FMS compared to controls: } \\
\text { IL-2 } \\
\text { IL-4 } \downarrow \\
\text { IL-8 } \leftrightarrow \\
\text { IL-10 } \downarrow \\
\text { TGF- } \beta 1 \leftrightarrow \\
\text { TNF } \leftrightarrow\end{array}$ & $3 d$ & 4 & 0.8 \\
\hline
\end{tabular}

Abbreviations:

ACR: American College of Rheumatology; CEMB: Center of Evidence Based Medicine; ELISA: enzyme linked immunosorbent assay; FMS: fibromyalgia syndrome; IL: interleukin; NOS: Newcastle Ottawa Scale; qRT-PCR: quantitative real-time PCR; W-MeQS: Würzburg Methodological Quality Score; yr: year

Table 7 Characteristics of studies investigating levels of cytokines in PBMC of FMS patients.

\begin{tabular}{|c|c|c|c|c|c|c|}
\hline $\begin{array}{l}\text { Author, } \\
\text { yr. } \\
\text { Diagnosis } \\
\text { criteria }\end{array}$ & $\begin{array}{l}\text { N patients/ } \\
\text { controls }\end{array}$ & $\begin{array}{l}\text { a) Material } \\
\text { b) Methods } \\
\text { c) Investigated targets }\end{array}$ & Results & $\begin{array}{l}\text { Modified } \\
\text { CEBM } \\
\text { level }\end{array}$ & NOS & $\begin{array}{l}\text { W- } \\
\text { MeQS }\end{array}$ \\
\hline $\begin{array}{l}\text { Hader, } \\
1991 \\
\text { Smythe }\end{array}$ & $12 / 10$ & $\begin{array}{l}\text { a) CD4+ T-lymphocytes from } \\
\text { PBMC } \\
\text { b) T-cell culture; stimulation } \\
\text { experiments with mitogens } \\
\text { c) IL-2 }\end{array}$ & $\begin{array}{l}\text { FMS: higher concentration of mitogen was } \\
\text { necessary to achieve optimal IL-2 secretion; peak } \\
\text { time of IL-2 secretion was delayed. } \\
\text { Addition of calcium did not correct the reduction } \\
\text { in IL-2 secretion in patients with FMS; addition of } \\
\text { phorbole myristate acetate led to normal IL-2 } \\
\text { secretion. }\end{array}$ & $3 d$ & 2 & 0.4 \\
\hline $\begin{array}{l}\text { Barth, } \\
1999 \\
\text { cite Wolfe, } \\
1985\end{array}$ & $\begin{array}{l}12 \mathrm{FMS} / 6 \\
\text { rheumatoid arthritis } \\
\text { or osteoarthritis } \\
\text { controls/6 }\end{array}$ & $\begin{array}{l}\text { a) supernatant of PBMC } \\
\text { b) in vitro stimulation of PBMC } \\
\text { with different L-tryptophan, } \\
\text { contaminated L-tryptophan, peak } \\
\text { E; } \\
\text { self established double sandwich } \\
\text { ELISA } \\
\text { C) IL-4, IL-2, INF- } \gamma \text {, GM-CSF, IL-5, } \\
\text { IL-10 }\end{array}$ & $\begin{array}{l}\text { In vitro stimulation of PBMC with different } \mathrm{L}- \\
\text { tryptophan preparations: } 6 / 12 \text { FMS patients, } 2 / 12 \\
\text { controls: IL-5 and IL-10 production }\end{array}$ & $3 d$ & 4 & 0.1 \\
\hline $\begin{array}{l}\text { Wallace, } \\
2001 \\
\text { ACR }\end{array}$ & $56 / 56$ & $\begin{array}{l}\text { a) serum, PBMC } \\
\text { b) ELISA } \\
\text { c) IL-1 } 1 \beta, I L-2, I L-6, I L-8, I L-10, \text { SIL-2 } \\
\text { R, IL-1 RA, IFN } \gamma \text {, TNF }\end{array}$ & $\begin{array}{l}\text { In FMS compared to controls: } \\
\text { IL-1 } 1 \beta, \text { IL-2, IL-10, sL-2 R, IFNy, TNF: } \leftrightarrow \text { in sera }+ \\
\text { PBMC } \\
\text { IL-1 RA, IL-8: } \Uparrow \text { in sera } \\
\text { IL-1 RA, IL-6: } \Uparrow \text { in PBMC } \\
\text { IL-6: } \Uparrow \text { in PBMC of patients with disease duration > } \\
2 \text { years. }\end{array}$ & $3 d$ & 3 & 0.5 \\
\hline $\begin{array}{l}\text { Amel } \\
\text { Kashipaz, } \\
2003 \\
\text { ACR }\end{array}$ & $22 \mathrm{FMS} / \mathrm{CFS} / 19$ & $\begin{array}{l}\text { a) PBMC } \\
\text { b) intracellular cytokine stain; } \\
\text { flow cytometry } \\
\text { c) IL-1 } \alpha, I L-6, I L-10, T N F\end{array}$ & $\begin{array}{l}\text { In FMS compared to controls: } \\
\text { IL-1 } \alpha \leftrightarrow \\
\text { IL- } 6 \leftrightarrow \\
\text { IL-10↔ } \\
\text { TNF } \leftrightarrow\end{array}$ & $3 d$ & 2 & 0.7 \\
\hline $\begin{array}{l}\text { Kaufmann, } \\
2007 \\
\text { ACR }\end{array}$ & 22/15 CRPS/37 & $\begin{array}{l}\text { a) T-cells } \\
\text { b) FACS analysis } \\
\text { c) IL-2, IFN-y, IL-4, IL-10 }\end{array}$ & $\begin{array}{l}\text { No difference in percentage of cytokine producing } \\
\text { cells between FMS and controls. }\end{array}$ & $3 d$ & 2 & 0.6 \\
\hline $\begin{array}{l}\text { Macedo, } \\
2007 \\
\text { ACR }\end{array}$ & $18 / 22$ & $\begin{array}{l}\text { a) blood, PBMC } \\
\text { b) automated biochip array; } \\
\text { before and after } 1.5 \mathrm{mg} \text { of } \\
\text { dexamethasone per os } \\
\text { c) IL-1 } \alpha, \mid \mathrm{L}-1 \beta \text {, IL-2, IL-4, IL-6, IL-8, } \\
\text { IL-10, IFN- } \gamma \text {, TNF }\end{array}$ & $\begin{array}{l}\text { After dexamethasone: reduction of cytokines FMS > } \\
\text { controls. }\end{array}$ & $3 d$ & 2 & 0.4 \\
\hline $\begin{array}{l}\text { Ortega, } \\
2010 \\
\text { ACR }\end{array}$ & $9 / 9$ & $\begin{array}{l}\text { a) PBMC } \\
\text { b) ELISA } \\
\text { c) IL-1b, TNF, IL-6, IL-10 }\end{array}$ & $\begin{array}{l}\text { For all cytokines investigated: higher values at } \\
\text { baseline in FMS compared to controls; after aquatic } \\
\text { exercise levels as in controls. }\end{array}$ & $3 d$ & 3 & 0.3 \\
\hline
\end{tabular}

Abbreviations:

ACR: American College of Rheumatology; CEMB: Center of Evidence Based Medicine; ELISA: enzyme linked immunosorbent assay; FMS: fibromyalgia syndrome; IL: interleukin; NOS: Newcastle Ottawa Scale; PBMC: peripheral blood mononuclear cells; R: receptor; RA: receptor antagonist; s: soluble; W-MeQS: Würzburg Methodological Quality Score; yr: year 
Table 8 Characteristics of studies investigating levels of cytokines in skin of FMS patients.

\begin{tabular}{|c|c|c|c|c|c|c|}
\hline $\begin{array}{l}\text { Author, yr. } \\
\text { Diagnosis } \\
\text { criteria }\end{array}$ & $\begin{array}{l}\text { N patients/ } \\
\text { controls }\end{array}$ & $\begin{array}{l}\text { a) Material } \\
\text { b) Methods } \\
\text { c) Investigated } \\
\text { targets }\end{array}$ & Results & $\begin{array}{l}\text { Modified } \\
\text { CEBM } \\
\text { level }\end{array}$ & NOS & $\begin{array}{l}\text { W- } \\
\text { MeQS }\end{array}$ \\
\hline $\begin{array}{l}\text { Salemi, } 2003 \\
\text { ACR }\end{array}$ & $53 / 10$ & $\begin{array}{l}\text { a) skin biopsy } \\
\text { b) RT-PCR, IHC } \\
\text { c) IL-1 } 1 \beta, I L-6 \text {, TNF }\end{array}$ & $\begin{array}{l}\text { Detectable cytokines in FMS: } \\
\text { IL-1 } 1 \beta(19 / 50) \\
\text { IL-6 }(14 / 51) \\
\text { TNF (17/53) } \\
\text { None of the cytokines could be detected in control } \\
\text { skin. }\end{array}$ & $3 d$ & 2 & 0.7 \\
\hline $\begin{array}{l}\text { Blanco, } 2010 \\
\text { ACR }\end{array}$ & $63 / 49$ & $\begin{array}{l}\text { a) skin } \\
\text { b) IHC } \\
\text { c) MCP-1, TNF }\end{array}$ & MCP-1: FMS < controls & $3 c$ & 3 & 0.8 \\
\hline
\end{tabular}

Abbreviations:

ACR: American College of Rheumatology; CEMB: Center of Evidence Based Medicine; FMS: fibromyalgia syndrome; IHC: immunohistochemistry; IL: interleukin; NOS: Newcastle Ottawa Scale; RT-PCR: reverse transcriptions PCR; W-MeQS: Würzburg Methodological Quality Score; yr: year

method. A group minimum of three studies was mandatory for meta-analysis.

A significant difference between controls and FMS was found only in two subgroups. When analyzing data of three studies on the pro-inflammatory cytokine IL-6 plasma levels investigated with ELISA or immunoassay or bioplex assay, patients with FMS had higher plasma levels of IL-6 compared to controls (SMD, -0.34; [-0.64, $-0.03]$ 95\% CI; $\mathrm{p}=0.03$; Table 4). There was also a trend for elevated serum IL-6 levels in FMS patients compared to controls (SMD, 1.01; $[-0.03,2.05] 95 \%[\mathrm{CI}] ; \mathrm{p}=0.06$ ). No further intergroup differences were found even when regarding studies investigating serum, plasma, and whole blood as one group of "blood" (Table 9).

Patients with FMS have higher plasma levels of IL-6 compared to controls. The discrepancy to the results of the systematic review (higher plasma IL-8 levels in patients with FMS) is due to the fact that only few studies were suitable for meta-analysis.

\section{Discussion}

In this systematic review and meta-analysis we set out to clarify if cytokine profiles in FMS patients differ from controls analyzing published data available to date. Applying the modified CEBM levels, NOS, and WMeQS we showed that the majority of the studies was of poor methodological quality. Our systematic review, in which we also considered study quality (modified CEBM level; NOS score; W-MeQS) shows that patients with FMS have higher serum IL-1RA, IL-6, and IL-8 levels compared to controls and that they also have higher plasma levels of IL-8. Looking at reproduced results (regardless of the method used and with a minimum of two independent studies) FMS patients do not differ from controls in serum IL-1 $\beta / \mathrm{IL}-1$, TNF, IL-2, IL10 , IFN- $\gamma$, and IL-4 levels; they also do not differ from controls in plasma IL-1 $\beta / \mathrm{IL}-1$, IL-6, TNF, IL-10, MCP1, IP10, IL-2, and IFN- $\gamma$ levels.
Our meta-analysis shows that patients with FMS have higher plasma levels of IL-6 compared to controls and a tendency for higher serum levels of IL-6 ( $p=0.06)$. No further differences could be found.

IL-1RA, IL-6, and IL-8 are pro-inflammatory cytokines that may have algesic effects. The role of cytokines in the induction and maintenance of pain is well established in animal studies and also in pain syndromes [5]. Therefore the hypothesis that patients with FMS, who suffer from generalized pain may have an innate or acquired imbalance in cytokine production and secretion is plausible. Higher levels of these cytokines in plasma and/or serum of patients with FMS may be associated with pain in FMS. In line with these findings one study showed lower levels of the anti-inflammatory and analgesic cytokines IL-4 and IL-10 in FMS patients compared to healthy controls [30]. However, it remains elusive, whether these systemic changes in cytokine levels are the cause of pain in FMS or its consequence. Longitudinal studies are needed to answer this question.

The main problem in interpreting the results of studies on cytokines in FMS is that although cytokines have been investigated in a large number of studies, different methods have been used to analyze different cytokines in diverse material. Therefore a direct comparison of the results is hardly possible. Results obtained for one cytokine have mostly not been reproduced, the number of samples investigated per study was low ( $7 / 25$ studies with $\mathrm{n}<20$ patients), and several studies report conflicting results - even in the same research group $[13,14]$. Also, possible confounding factors that physiologically may influence cytokine levels (e.g. circadian production; depression; physical activity; current infection) were not controlled in the majority of the studies.

Another problem is that the measurements mostly were not specifically hypothesis-driven, but were performed following the general assumption that "cytokines may play a role". Therefore in the majority of studies a 
Table 9 Results of meta-analysis.

\begin{tabular}{|c|c|c|c|c|c|c|c|c|}
\hline \multirow[t]{2}{*}{ Study } & \multicolumn{3}{|l|}{ FMS } & \multicolumn{3}{|c|}{ Controls } & \multirow[t]{2}{*}{ Weight } & \multirow{2}{*}{$\begin{array}{l}\text { SMD } \\
\text { IV, Random, 95\% Cl }\end{array}$} \\
\hline & Mean & Std & Total & Mean & Std & Total & & \\
\hline \multicolumn{9}{|c|}{ IL-1: plasma, ELISA or immunoassay } \\
\hline Togo 2009 & 0.79 & 0.64 & 7 & 1.24 & 1.17 & 9 & $16.4 \%$ & $-0.43[-1.44,0.57]$ \\
\hline Feng 2009 & 74.5 & 116.5 & 100 & 45.6 & 53.1 & 35 & $41.3 \%$ & $0.28[-0.11,0.66]$ \\
\hline Bazzichi 2007 & 4.54 & 9.7 & 80 & 7.44 & 6.62 & 45 & $42.3 \%$ & $-0.33[-0.70,0.04]$ \\
\hline Total $(95 \% \mathrm{Cl})$ & & & 187 & & & 89 & $100.0 \%$ & $-0.10[-0.58,0.39]$ \\
\hline \multicolumn{9}{|c|}{ Heterogeneity: $\operatorname{Tau}^{2}=0.11 ; \mathrm{Chi}^{2}=5.52, \mathrm{df}=2(\mathrm{P}=0.06) ; \mathrm{I}^{2}=64 \%$} \\
\hline \multicolumn{9}{|c|}{ Test for overall effect: $Z=0.39(P=0.69)$} \\
\hline \multicolumn{9}{|c|}{ IL-6: plasma, ELISA or immunoassay or bioplex assay } \\
\hline Togo 2009 & 14.0 & 10.9 & 7 & 16.8 & 15.3 & 9 & $9.6 \%$ & $-0.19[-1.19,0.80]$ \\
\hline Schwarz 2002 & 1.01 & 0.47 & 17 & 1.45 & 2.17 & 17 & $20.7 \%$ & $-0.27[-0.95,0.40]$ \\
\hline Bazzichi 2007 & 2.76 & 3.99 & 80 & 4.34 & 4.51 & 45 & $69.7 \%$ & $-0.38[-0.74,-0.01]$ \\
\hline Total $(95 \% \mathrm{Cl})$ & & & 104 & & & 71 & $100.0 \%$ & $-0.34[-0.64,-0.03]$ \\
\hline \multicolumn{9}{|c|}{ Heterogeneity: Tau $^{2}=0.00 ; \mathrm{Chi}^{2}=0.15, \mathrm{df}=2(\mathrm{P}=0.93) ; \mathrm{I}^{2}=0 \%$} \\
\hline \multicolumn{9}{|c|}{ Test for overall effect: $Z=2.15(P=0.03)$} \\
\hline \multicolumn{9}{|c|}{ IL-6: serum, ELISA or immunoassay or bioplex assay } \\
\hline Gür 2002 & 5.52 & 3.96 & 81 & 5.46 & 1.37 & 32 & $25.7 \%$ & $0.02[-0.39,0.43]$ \\
\hline Hernandez 2010 & 16.28 & 8.13 & 64 & 0.92 & 0.32 & 25 & $24.8 \%$ & $2.20[1.63,2.77]$ \\
\hline Wallace 2001 & 7.19 & 2.02 & 56 & 6.3 & 6.72 & 36 & $25.6 \%$ & $0.20[-0.22,0.62]$ \\
\hline Wang 2008 & 2.57 & 1.38 & 20 & 0.92 & 0.32 & 25 & $23.9 \%$ & $1.71[1.02,2.40]$ \\
\hline Total $(95 \% \mathrm{Cl})$ & & & 221 & & & 118 & $100.0 \%$ & $1.01[-0.03,2.05]$ \\
\hline \multicolumn{9}{|c|}{ Heterogeneity: $\operatorname{Tau}^{2}=1.05 ; \mathrm{Chi}^{2}=51.09, \mathrm{df}=3(\mathrm{P}<0.00001) ; 1^{2}=94 \%$} \\
\hline \multicolumn{9}{|c|}{ Test for overall effect: $Z=1.91(P=0.06)$} \\
\hline \multicolumn{9}{|c|}{ IL-8: plasma, ELISA or immunoassay } \\
\hline Bazzichi 2007 & 61.89 & 149.0 & 80 & 7.9 & 17.5 & 45 & $41.2 \%$ & $0.45[0.08,0.82]$ \\
\hline Blanco 2010 & 83.0 & 253.0 & 79 & 84.0 & 253.0 & 59 & $42.8 \%$ & $-0.00[-0.34,0.33]$ \\
\hline Togo 2009 & 8.4 & 1.9 & 7 & 11.8 & 5.4 & 9 & $16.0 \%$ & $-0.75[-1.79,0.28]$ \\
\hline Total $(95 \% \mathrm{Cl})$ & & & 166 & & & 113 & $100.0 \%$ & $0.06[-0.43,0.56]$ \\
\hline \multicolumn{9}{|c|}{ Heterogeneity: $\operatorname{Tau}^{2}=0.12 ; \mathrm{Chi}^{2}=6.23, \mathrm{df}=2(\mathrm{P}=0.04) ; \mathrm{I}^{2}=68 \%$} \\
\hline \multicolumn{9}{|c|}{ Test for overall effect: $Z=0.25(P=0.80)$} \\
\hline \multicolumn{9}{|c|}{ TNF: serum, ELISA or immunoassay or bioplex assay } \\
\hline Hernandez 2010 & 20.42 & 7.24 & 64 & 35.73 & 0.72 & 25 & $33.0 \%$ & $-2.46[-3.05,-1.87]$ \\
\hline Wang 2008 & 3.27 & 5.08 & 20 & 3.89 & 12.95 & 80 & $33.5 \%$ & $-0.05[-0.54,0.44]$ \\
\hline Üçeyler 2006 & 7.41 & 11.01 & 26 & 6.7 & 9.5 & 40 & $33.5 \%$ & $0.07[-0.42,0.56]$ \\
\hline Total $(95 \% \mathrm{Cl})$ & & & 110 & & & 145 & $100.0 \%$ & $-0.81[-2.31,0.70]$ \\
\hline \multicolumn{9}{|c|}{ Heterogeneity: Tau $^{2}=1.70 ; \mathrm{Chi}^{2}=49.74, \mathrm{df}=2(\mathrm{P}<0.00001) ;\left.\right|^{2}=96 \%$} \\
\hline \multicolumn{9}{|c|}{ Test for overall effect: $Z=1.05(P=0.29)$} \\
\hline \multicolumn{9}{|c|}{ TNF: plasma, ELISA or immunoassay } \\
\hline Bazzichi 2007 & 22.59 & 29.55 & 80 & 11.07 & 6.77 & 45 & $28.0 \%$ & $0.48[0.11,0.85]$ \\
\hline Blanco 2010 & 163.0 & 435.0 & 79 & 161.0 & 319.0 & 59 & $28.5 \%$ & $0.01[-0.33,0.34]$ \\
\hline Feng 2009 & 12.2 & 10.2 & 100 & 40.1 & 73.5 & 35 & $27.6 \%$ & $-0.73[-1.12,-0.33]$ \\
\hline Togo 2009 & 0.24 & 0.13 & 7 & 0.7 & 0.61 & 9 & $16.0 \%$ & $-0.93[-1.98,0.13]$ \\
\hline Total $(95 \% \mathrm{Cl})$ & & & 266 & & & 148 & $100.0 \%$ & $-0.21[-0.82,0.39]$ \\
\hline \multicolumn{9}{|c|}{ Heterogeneity: Tau $^{2}=0.30 ; \mathrm{Chi}^{2}=21.71, \mathrm{df}=3(\mathrm{P}<0.0001) ; \mathrm{I}^{2}=86 \%$} \\
\hline Test for overall e & $z=0.69$ & 0.49) & & & & & & \\
\hline
\end{tabular}


large array of cytokines was screened without a clear hypothesis for each cytokine. This might be one reason why only few markers were repetitively analyzed, however, most markers were investigated only once - probably because they were part of a commercially available kit. In none of the studies a mechanistical approach was followed to investigate the mechanisms possibly underlying the effect of a specific cytokine in the induction and maintenance of defined symptoms of FMS. Therefore also the biological impact of the described changes in cytokine levels remains elusive. The question is also if in all studies the most appropriate method was used to detect the cytokine of interest. The majority of cytokines have a low expression and it is essential to apply methods that are sensitive enough. In the last years high- and ultra-sensitive bioassays have been developed that reliably allow the determination of cytokine proteins in body fluids. Since in the majority of cytokine studies analyzed here the sensitivity of the used method was not given it is not clear if the many negative results reported are "real" or due to low method sensitivity.

One further point is that there is no validated scoring system for the quality of laboratory methods in research papers. Such tools, however, are needed to assess study results and to compare the results of different studies, especially when looking at conflicting results. Standardization of the way laboratory research is performed by following quality standards and its presentation is warranted. The quality score $\mathrm{W}-\mathrm{MeQS}$ that we present here may be one possibility.

In many cases the data provided in the papers were not applicable for meta-analysis and could not be calculated from the data presented in the publication. This fact and the diversity of methods and materials investigated made it almost impossible to form subgroups for meta-analysis.

Cytokines form a "fragile" system that can be influenced by many factors. The following issues might help improving the quality and the yield of future cytokine research in FMS patients: 1) Cytokine secretion follows circadian rhythmicity; the time points of material asservation should be kept constant. 2) Cytokine secretion has a large variability; measurements should be performed on two sets of samples and at least two different methods should be used (e.g. investigation of gene expression and protein levels). 3) Cytokine levels can be influenced by many environmental factors and by medication; patients should therefore be off medication at the time of material asservation or the possible influence of medication should be considered when interpreting the results. 4) Detailed patient characteristics (including disease duration; pattern of symptoms etc.) are essential for correlation of the cytokine measurements with clinical data. 5) The formulation of a clear literature-based hypothesis is warranted at the beginning of the cytokine study and a power calculation should be performed in advance. 6) Systemic and local cytokine expression should be investigated with appropriate methods. To choose the appropriate method, the expected level of expression should be taken into account and it should be made sure that the sensitivity of the method used is high enough to measure what is to be measured.

\section{Conclusions}

The major consequence of our review is that cytokine research in FMS pathophysiology needs substantial improvement. More hypothesis-based and mechanistic studies are needed to understand if distinct cytokines are involved in causing symptoms of FMS or if they may be used as biomarkers of FMS symptoms. There is also a need for defined and applied quality standards for study design and performance in bench-side research and for standardization rules for study reports and manuscripts (like STROBE for clinical research). Possible confounding factors of cytokine levels should be controlled and a sufficient number of study subjects should be investigated e.g. following an a priori power calculation of sample size. Also the performance of prospective studies would be helpful.

\section{List of abbreviations}

CEBM: Center for Evidence Based Medicine; FMS: fibromyalgia syndrome; GM-CSF: granulocyte macrophage colony-stimulating factor; IFN: interferon; IL: interleukin; IP-10: interferon gamma-induced protein-10; NOS: NewcastleOttawa Scale; MCP-1: monocyte chemoattractant protein-1; MIP-1: macrophage inflammatory protein-1; PBMC: peripheral blood mononuclear cells; R: receptor; RA: receptor antagonist; s: soluble; SMD: standardized mean differences; TGF: transforming growth factor; TNF: tumor necrosis factor-a; W-MeQS: Würzburg Methodological Quality Score.

\section{Acknowledgements}

We thank E. Friedrich-Würstlein, A. Götz, A. Horch, and A. May for help during article selection and screening. The authors' work was supported by intramural funds of the University of Würzburg. The publication was funded by the German Research Foundation (DFG) and the University of Würzburg in the funding programme Open Access Publishing.

\section{Author details}

'Department of Neurology, University of Würzburg, Josef-Schneider-Str. 11, 97080 Würzburg, Germany. ${ }^{2}$ Center of Pain Therapy, Klinikum Saarbrücken gGmbH, Winterberg 1, 66119 Saarbrücken, Germany. ${ }^{3}$ Department of Psychosomatic Medicine and Psychotherapie, Technische Universität München, Ismaningerstraße 22, 81675 München, Germany.

\section{Authors' contributions}

NÜ performed literature search, extracted and analyzed the data, generated Tables and Figures, and prepared manuscript. WH participated in data analysis and manuscript preparation. CS participated in literature search, data extraction, data analysis and manuscript preparation. All authors have read and approved the final manuscript before submission for peer review.

\section{Competing interests}

The authors declare that they have no competing interests.

Received: 18 August 2011 Accepted: 28 October 2011 Published: 28 October 2011 


\section{References}

1. Wolfe F, Smythe HA, Yunus MB, Bennett RM, Bombardier C, Goldenberg DL, Tugwell P, Campbell SM, Abeles M, Clark P, et al: The American College of Rheumatology 1990 Criteria for the Classification of Fibromyalgia. Report of the Multicenter Criteria Committee. Arthritis and rheumatism 1990, 33:160-172.

2. Häuser W, Zimmer C, Felde E, Kollner V: [What are the key symptoms of fibromyalgia? Results of a survey of the German Fibromyalgia Association]. Schmerz (Berlin, Germany) 2008, 22:176-183.

3. Branco JC, Bannwarth B, Failde I, Abello Carbonell J, Blotman F, Spaeth M, Saraiva F, Nacci F, Thomas E, Caubere JP, et al: Prevalence of fibromyalgia: a survey in five European countries. Semin Arthritis Rheum 2010, 39:448-453.

4. Lawrence RC, Felson DT, Helmick CG, Arnold LM, Choi H, Deyo RA, Gabriel S, Hirsch R, Hochberg MC, Hunder GG, et al: Estimates of the prevalence of arthritis and other rheumatic conditions in the United States. Part II. Arthritis and rheumatism 2008, 58:26-35.

5. Üçeyler N, Sommer C: Cytokine regulation in animal models of neuropathic pain and in human diseases. Neurosci Lett 2008, 437:194-198.

6. Menzies V, Lyon DE: Integrated review of the association of cytokines with fibromyalgia and fibromyalgia core symptoms. Biol Res Nurs 2010, 11:387-394.

7. Gür A, Oktayoğlu P: Status of immune mediators in fibromyalgia. Current pain and headache reports 2008, 12:175-181.

8. Bernardy K, Klose P, Üçeyler N, Kopp I, Hauser W: [Methodological fundamentals for the development of the guideline.]. Schmerz (Berlin, Germany) 2008.

9. Centre. TNC: Review Manager (RevMan). 5.0 for Windows edn Copenhagen: The Cochrane Collaboration; 2010.

10. Amel Kashipaz MR, Swinden D, Todd I, Powell RJ: Normal production of inflammatory cytokines in chronic fatigue and fibromyalgia syndromes determined by intracellular cytokine staining in short-term cultured blood mononuclear cells. Clinical and experimental immunology 2003 132:360-365.

11. Ardıç F, Özgen M, Aybek H, Rota S, Çubukçu D, Gökgöz A: Effects of balneotherapy on serum IL-1, PGE2 and LTB4 levels in fibromyalgia patients. Rheumatology international 2007, 27:441-446.

12. Barth $H$, Berg PA, Klein $R$ : Is there any relationship between eosinophilia myalgia syndrome (EMS) and fibromyalgia syndrome (FMS)? An analysis of clinical and immunological data. Advances in experimental medicine and biology 1999, 467:487-496.

13. Bazzichi L, Giacomelli C, De Feo F, Giuliano T, Rossi A, Doveri M, Tani C, Wilson RB, Bombardieri S: Antipolymer antibody in Italian fibromyalgic patients. Arthritis research \& therapy 2007, 9:R86.

14. Bazzichi L, Rossi A, Massimetti G, Giannaccini G, Giuliano T, De Feo F, Ciapparelli A, Dell'Osso L, Bombardieri S: Cytokine patterns in fibromyalgia and their correlation with clinical manifestations. Clinical and experimental rheumatology 2007, 25:225-230.

15. Blanco I, Beritze N, Arguelles M, Carcaba V, Fernandez F, Janciauskiene S, Oikonomopoulou K, de Serres FJ, Fernandez-Bustillo E, Hollenberg MD: Abnormal overexpression of mastocytes in skin biopsies of fibromyalgia patients. Clinical rheumatology 2010, 29:1403-1412.

16. Blanco I, Janciauskiene S, Nita I, Fernandez-Bustillo E, Carcaba V, Gallo C, Alvarez-Rico M, de Serres F, Beridze N: Low plasma levels of monocyte chemoattractant protein-1 (MCP-1), tumor necrosis factor-alpha (TNFalpha), and vascular endothelial growth factor (VEGF) in patients with alpha1-antitrypsin deficiency-related fibromyalgia. Clinical rheumatology 2010, 29:189-197.

17. Feng J, Zhang Z, Li W, Shen X, Song W, Yang C, Chang F, Longmate J, Marek C, St Amand RP, et al: Missense mutations in the MEFV gene are associated with fibromyalgia syndrome and correlate with elevated IL1beta plasma levels. PloS one 2009, 4:e8480.

18. Hader N, Rimon D, Kinarty A, Lahat N: Altered interleukin-2 secretion in patients with primary fibromyalgia syndrome. Arthritis and rheumatism 1991, 34:866-872.

19. Hernandez ME, Becerril E, Perez M, Leff P, Anton B, Estrada S, Estrada I, Sarasa $M$, Serrano $E$, Pavon L: Proinflammatory cytokine levels in fibromyalgia patients are independent of body mass index. BMC research notes 2010, 3:156.

20. lannuccelli C, Di Franco M, Alessandri C, Guzzo MP, Croia C, Di Sabato F, Foti M, Valesini G: Pathophysiology of fibromyalgia: a comparison with the tension-type headache, a localized pain syndrome. Annals of the New York Academy of Sciences 2010, 1193:78-83.

21. Kaufmann I, Eisner C, Richter P, Huge V, Beyer A, Chouker A, Schelling G, Thiel M: Lymphocyte subsets and the role of $\mathrm{TH} 1 / \mathrm{TH} 2$ balance in stressed chronic pain patients. Neuroimmunomodulation 2007, 14:272-280.

22. Macedo JA, Hesse J, Turner JD, Ammerlaan W, Gierens A, Hellhammer DH, Muller CP: Adhesion molecules and cytokine expression in fibromyalgia patients: increased L-selectin on monocytes and neutrophils. Journal of neuroimmunology 2007, 188:159-166.

23. Maes M, Libbrecht I, Van Hunsel F, Lin AH, De Clerck L, Stevens W, Kenis G,


pathophysiology of fibromyalgia: increased serum soluble gp130, the common signal transducer protein of various neurotrophic cytokines. Psychoneuroendocrinology 1999, 24:371-383.

24. Ortega E, Bote ME, Giraldo E, Garcia JJ: Aquatic exercise improves the monocyte pro- and anti-inflammatory cytokine production balance in fibromyalgia patients. Scandinavian journal of medicine \& science in sports 2010.

25. Pay S, Çalgüneri M, Çalışkaner Z, Dinç A, Apras S, Ertenli I, Kiraz S, Cobankara V: Evaluation of vascular injury with proinflammatory cytokines, thrombomodulin and fibronectin in patients with primary fibromyalgia. Nagoya journal of medical science 2000, 63:115-122.

26. Ross RL, Jones KD, Bennett RM, Ward RL, Druker BJ, Wood LJ: Preliminary Evidence of Increased Pain and Elevated Cytokines in Fibromyalgia Patients with Defective Growth Hormone Response to Exercise. The open immunology journal 2010, 3:9-18.

27. Salemi S, Rethage J, Wollina U, Michel BA, Gay RE, Gay S, Sprott H: Detection of interleukin 1 beta (IL-1beta), IL-6, and tumor necrosis factoralpha in skin of patients with fibromyalgia. The Journal of rheumatology 2003, 30:146-150.

28. Schwarz MJ, Offenbaecher M, Neumeister A, Ewert T, Willeit M, PraschakRieder N, Zach J, Zacherl M, Lossau K, Weisser R, et al: Evidence for an altered tryptophan metabolism in fibromyalgia. Neurobiology of disease 2002, 11:434-442

29. Togo F, Natelson BH, Adler GK, Ottenweller JE, Goldenberg DL, Struzik ZR, Yamamoto Y: Plasma cytokine fluctuations over time in healthy controls and patients with fibromyalgia. Experimental biology and medicine (Maywood, NJ 2009, 234:232-240.

30. Üçeyler N, Valenza R, Stock M, Schedel R, Sprotte G, Sommer C: Reduced levels of antiinflammatory cytokines in patients with chronic widespread pain. Arthritis Rheum 2006, 54:2656-2664.

31. Wallace DJ, Linker-Israeli M, Hallegua D, Silverman S, Silver D, Weisman MH: Cytokines play an aetiopathogenetic role in fibromyalgia: a hypothesis and pilot study. Rheumatology (Oxford, England) 2001, 40:743-749.

32. Wang $H$, Moser $M$, Schiltenwolf $M$, Buchner $M$ : Circulating cytokine levels compared to pain in patients with fibromyalgia - a prospective longitudinal study over 6 months. The Journal of rheumatology 2008 35:1366-1370.

33. Zhang Z, Cherryholmes G, Mao A, Marek C, Longmate J, Kalos M, Amand RP, Shively JE: High plasma levels of MCP-1 and eotaxin provide evidence for an immunological basis of fibromyalgia. Experimental biology and medicine (Maywood, NJ) 2008, 233:1171-1180.

34. Gür A, Karakoç M, Nas K, Remzi , Çevik, Denli A, Saraç J: Cytokines and depression in cases with fibromyalgia. The Journal of rheumatology 2002, 29:358-361.

\section{Pre-publication history}

The pre-publication history for this paper can be accessed here: http://www.biomedcentral.com/1471-2474/12/245/prepub

doi:10.1186/1471-2474-12-245

Cite this article as: Üçeyler et al:: Systematic review with meta-analysis: cytokines in fibromyalgia syndrome. BMC Musculoskeletal Disorders 2011 $12: 245$. 